\title{
Cultura, identidades y transculturalidad. Apuntes sobre LA CONSTRUCCIÓN IDENTITARIA DE LAS JUVENTUDES INDÍGENAS
}

\author{
Juan Pablo Zebadúa Carbonell
}

Resumen: Este trabajo analiza conceptualmente la construcción de las identidades juveniles indígenas a partir de su inserción en los contextos globales. Se analizan críticamente las identidades desde la cultura, y, consecuentemente, desde la transculturalidad, como un proceso social mediante el cual se construyen las identidades juveniles de la actualidad, particularizando en las identidades juveniles indígenas. En este recorrido se observan directrices analíticas para entender la aparición de grupos de jóvenes indígenas con nuevas formas de agregación identitaria, además de que permite tener miradas criticas en torno a lo juvenil indígena.

Palabras clave: Cultura, identidades, transculturalidad, globalización, juventudes indígenas.

Enviado a dictamen: 25 de abril de 2011

Aprobación: 26 de mayo de 2011

Revisiones: 1

Juan Pablo Zebadúa Carbonell, es Doctor en Estudios Interculturales y Sociedades Multiculturales por la Universidad de Granada, España. Actualmente trabaja en la Universidad Veracruzana Intercultural (UVI), donde es Profesor Investigador de Tiempo Completo y miembro del Departamento de Comunicación. Temas de especialización: juventud y culturas juveniles. Actualmente desarrolla un proyecto de investigación sobre identidades de jóvenes indígenas en la UVI. Correo electrónico: jpzebadua@gmail.com.
Abstract: The followingwork analyzes conceptually the construction of indigenous youth identities through their insertion into global contexts. They are critically analyzed through their culture and identities, and consequentially through transculturality, which it is understood as a social process through which current youth identities are developed, particularly indigenous youth identities. Through this document analytical guidelines are considered, to understand the emergence of indigenous youth groups which develop new forms of identity. In addition these theoretical approaches motivate a more critical analysis of indigenous youth affairs.

Keywords: Culture, identity, transcultural, globalization, indigenous youth.

\section{Introducción}

$\mathrm{L}$ as siguientes líneas aportan elementos conceptuales para abordar los análisis de las identidades juveniles en la contemporaneidad, específicamente en las juventudes indígenas. Se colocan a debate nuevas formas de entender lo joven indígena y se promueve el fortalecimiento de otras miradas y perspectivas para su estudio, en tanto que éstas están inmersas en procesos que actualmente se desarrollan en las escenas internacionales. 
Hoy día, los universos étnicos indígenas han asumido una serie de cambios en función de diversos y complejos factores externos a las culturas originales de los pueblos indios como consecuencia de los actuales contextos globales que sobresalen en el mundo. También lo étnico es un espacio cultural donde se reproducen dichas dinámicas internacionales, de tal forma que las repercusiones en torno a los condicionamientos sociales de las regiones autóctonas son cada vez más notorias a partir de los cambios suscitados en la actualidad.

En todos los casos son las juventudes indígenas quienes acusan más ese sentido de cambio debido a la relación directa que tienen con los entornos de la globalización, por ejemplo, en la decisiva influencia de los medios de comunicación y el consumo cultural, antes no tan determinantes en las regiones étnicas, que ahora ya forman parte de sus realidades.

Lo que a continuación se presenta forma parte de la necesidad de analizar a las juventudes indígenas desde una visión no estandarizada ni reducida del joven indígena, sino desde una perspectiva que visibilice sus construcciones identitarias a partir de las nuevas prácticas culturales suscitadas en grupos de jóvenes que han transformado su propia condición social en las comunidades donde se desenvuelven. Estas nuevas prácticas, inéditas en los jóvenes indígenas, han logrado que sus identidades se manifiesten en procesos que apuestan a los constantes préstamos de elementos culturales aparentemente ajenos, así como al reutilizamiento de éstos para después hacerlos visibles en nuevas y distintas adscripciones.

Todo ello predomina ya sea desde "lo local" como desde "lo global", entrando y saliendo de su condición juvenil indígena cuantas veces sea necesario y creando nuevos modelos identitarios juveniles. A este proceso le llamamos "identidades juveniles transculturales" como parte de los nuevos escenarios de las juventudes indígenas en las regiones étnicas del país.

En este artículo se observan las identidades indígenas desde un horizonte explicativo que da cuenta de las nuevas formas de adscripción identitaria juvenil indígena desarrollando tres conceptos: la cultura, las identidades, la transculturalidad. Se analiza la cultura como una necesidad de entender las realidades étnicas desde posturas epistémicas no esencializadas sino reformuladas y dirigidas hacia la puntual comprensión de problemáticas actuales, así como las identidades como parte de su actual "multiplicidad" y sus formas de explicar los actuales "sentidos" de adscripción de las juventudes indígenas. Y por último, la transculturalidad como un proceso social donde se desarrollan constructos identitarios multiplicados que se concibe también como un proceso de flexibilización de fronteras culturales. Con el despliegue de estos conceptos podemos observar los cambios culturales suscitados actualmente en los jóvenes indígenas, cómo están construyendo sus identidades y cómo estas nuevas identidades se distinguen como parte de las retroalimentaciones que estos jóvenes efectúan, desde adentro y desde afuera, de sus propias realidades.

\section{Contextos globales y las etnias}

Es verdad que son las juventudes quienes dentro de la globalización están percibiendo y generando una serie de cambios, tan rápidos y tan significativos, que advierten nuevas formas de estar en el mundo centralmente en la construcción de sus identidades (Valenzuela, 2009; Zebadúa, 2009). Esto ya es extensivo a las juventudes indígenas quienes también forman parte de dichas dinámicas globales, ya que sus regiones y comunidades han sobrellevado importantes fenómenos sociales que han modificado sus estructuras sociales, culturales y económicas.

Por ejemplo el fenómeno social de la migración, que no nada más representa una problemática de las regiones étnicas, sino también del mundo entero, pero donde sí podemos distinguir en los pueblos indígenas esquemas de exclusión de sectores enteros de la población. Esto se amplía hacia una problematización 
comunitaria general porque lo que está en juego es la preeminencia cultural de las etnias en los tiempos presentes. En el ámbito cultural, el dilema se cierne en torno a los alcances de este continuo encuentro y desencuentro con la globalización, y cómo los colectivos se erigen estratégicamente anteponiendo sus valores comunitarios y locales para al mismo tiempo estar adentro y afuera, además que todo esto se encuentra cruzado por distintos entramados discursivos, simbólicos y participativos.

Esta posición —ciertamente estratégica- de las etnias ha logrado que su permanencia en el tiempo y en el espacio sea una realidad, pero haciendo prevalecer sus modelos culturales que ahora se retroalimentan de los procesos de la globalización. En el caso de la migración, la medición de su impacto tiene mucho que ver con estas reelaboraciones culturales que las comunidades indígenas realizan constantemente (Imaz, 2006: 237).

Es una necesidad la de plantear de manera distinta el quehacer analítico en torno a los cambios en los pueblos indígenas, ahí donde es fácilmente perceptible "exotizar" a las culturas étnicas, o de "fabricar la alteridad", como expresa Ghasarian (2009: 25). Esta posición todavía se presenta cuando se observan a estos grupos como homogéneos e inmutables a cualquier tipo de cambio, como anclados en el tiempo, donde en aras de la preservación de sus convenciones culturales ancestrales no tienen por qué estar en contacto con las realidades externas y mucho menos ser influenciados por éstas. Tales visiones pueden derivar en perspectivas que no tengan que ver con el análisis de los propios movimientos y evidentes transformaciones culturales que desde hace mucho tiempo enfrentan las etnias con respecto a lo global.

Por tanto, es pertinente la reflexión actualizada sobre la condición indígena y sus nuevas elaboraciones culturales en los actuales contextos: las comunidades indígenas son otras a partir de que han sido impactadas desde varios frentes y procesos, desde lo cultural, lo económico, lo social, donde los movimientos migratorios son decisivos a la hora de conformar los sentidos de las sociedades indígenas y las apropiaciones culturales de diversos orígenes están a la orden del día. En todos los casos, los grupos étnicos reflexionan estas dinámicas globales y a su manera actualizan sus matrices culturales que les permite seguir en la autoafirmación identitaria.

\section{Las juventudes indígenas}

Lo anterior atañe directamente a las juventudes indígenas. Son los jóvenes quienes más acusan el sentido de cambio y reciclan constantemente el accionar de sus propios universos en relación con las instancias externas con las que constantemente conviven.

El estudio de las juventudes indígenas es relativamente nuevo en las ciencias sociales, en particular en los campos de los estudios étnicos. La visibilización de este sector se debe en parte a las prácticas culturales que los/as jóvenes indígenas realizan en la actualidad por su interpelación hacia los global, que ya incide significativamente en las juventudes de las regiones étnicas. Otra de las causas es que la antropología ha dado un giro en sus horizontes explicativos y ahora voltea a otros sujetos que antes no tenían importancia para los análisis de campo (Guerrero, 2002; Hernández y del Olmo, 2005: 19-26).

Respecto a las nuevas prácticas juveniles hay dos que sobresalen: sus manifiestas adscripciones a los lenguajes de los medios masivos de comunicación y el consumo cultural. Como elementos "emergentes" en la vida social de los jóvenes indígenas, han logrado establecer nuevos comportamientos y también nuevas formas de socialización en la vida comunitaria:

La identidad indígena juvenil [...] no es ajena a los efectos simbólicos y comunicacionales que la globalización cultural, por vía del consumo cultural (de bienes, servicio e imaginarios), genera en su identidad, como sucede en otras latitudes geográficas 
[...] sectores como el de los mayores, las mujeres y los ancianos comparten similares criterios de identidad: como el telúrico — territorial, y arraigado a la organización, la tradición y las costumbres-, mientras que el sector de los jóvenes se identifica también con otro tipo de elementos culturales no territoriales (deterritorializados), es atraído por los bienes culturales y de moda (vestimenta y música principalmente) y presenta comportamientos individualistas, entre otras cosas (Terrazas, 2008: 142).

No obstante, es necesario advertir que si bien la construcción identitaria juvenil indígena está enmarcada en ciertas directrices importantes de la globalización ello no quiere decir que signifique la pérdida total de la cultura comunitaria ni que se voltee la espalda a las tradiciones (Pérez, 2008: 33). Por el contrario, estas nuevas elaboraciones de identidad juvenil tienen como característica el que recorren distintas fronteras y se adscriben indistintamente a patrones culturales que son relevantes en el momento de la apropiación. Los jóvenes indígenas pueden entrar y salir de los límites comunitarios, en apariencia inamovibles, como parte del proceso en el cual el tiempo y el espacio comunitario se modifican transculturalmente y permite en los jóvenes la negociación constante de sus propias prácticas, entre ellos mismos y con la comunidad en general.

Estas juventudes están agregando a sus referentes una considerable cantidad de elementos que provienen de fuera de sus culturas originales pero, al mismo tiempo, ello hace que renueven su esencia y las hace identificarse como parte de un proceso que a veces va más allá de su comunidad, incluso en espacios transnacionales. Elementos como la moda, la música (especialmente el pop, el reguetón y el rock, en las regiones rurales e indígenas) y la mencionada influencia de los medios de comunicación masiva hace de los jóvenes indígenas una interesante composición cultural que necesariamente repercute en la manera de ver el mundo y sus construcciones identitarias.

\section{El contexto cultural}

Para entender estas transformaciones identitarias se impone una conceptualización de la cultura desde nuevas perspectivas (Guerrero, 2002: 126) y así tener los alcances epistemológicos necesarios que expliquen las profundas transformaciones sociales que acontecen en nuestros días. En lo que concierne a las reflexiones sobre esto, en la actualidad es evidente la presencia del concepto de cultura respecto al horizonte con que se observan los procesos humanos. Nunca antes dicho concepto había estado tan actualizado como ahora en las ciencias sociales. ${ }^{1}$

Cada vez más la cultura se parece a un paradigma de conocimiento en que se intercambian nuevos enfoques que explican una serie de procesos que antes atañían a distintos horizontes conceptuales, pero en donde la cultura surge con vigor como demarcación epistemológica y centra el debate académico a nivel internacional. Todo ello nos lleva a pensar en la dimensión que este concepto ha adquirido en los últimos años y la extensión de sus alcances cuando hasta hace poco tiempo el concepto se relegaba exclusivamente al campo específico antropológico.

Al entrar la cultura en los análisis de problemáticas contemporáneas, el concepto tiene que adoptarse no para demandar explicaciones con carácter universal sino como un constructo reelaborado constantemente por los actores involucrados en tanto sujetos partícipes de su propia dinámica social. La cultura aquí es concebida como una elaboración conjunta, grupal y comunitaria, que no podemos percibirla como un todo ni como algo ya dado, con carácter esencial para los miembros del grupo. La orientación analítica de la cultura, como una construcción permanente y cotidiana, es ahora una exigencia epistémica porque el entendimiento de la realidad no puede reconocerse 
como una totalidad sino como persistente dialéctica entre los integrantes de la sociedad de frente a los factores externos que acometen sistemáticamente con la cotidianidad.

Esta noción de cultura como constructo nos remite a esa reelaboración de la práctica simbólica como parte de la dialéctica de las relaciones entabladas al interior del grupo social. De ello se nutre Thompson (1998) para proponer un concepto "estructural" de la cultura, como una noción de carácter simbólico fijada y situada en particulares contextos sociales:

Es una concepción de la cultura que enfatiza tanto el carácter simbólico de los fenómenos culturales como el hecho de que tales fenómenos se inserten siempre en contextos sociales estructurados [...] (La cultura) se puede considerar como el estudio de la constitución significativa y la contextualización social de las formas simbólicas [...] El análisis de los fenómenos culturales implica elucidar estos contextos y procesos estructurados socialmente, así como interpretar las formas simbólicas [...] Implica interpretar las formas simbólicas por medio del análisis de contextos y procesos estructurados (Thompson, 1998: 203).

Se intenta así superar la visión de cultura de Geertz, quien la plantea como un proceso esencialmente simbólico sin tomar en cuenta su presencia en situaciones determinadas dialécticamente por los propios actores/actoras en dichos procesos y circunstancias sociales:

Indudablemente la reformulación de Clifford Geertz ha marcado un giro importante en la literatura antropológica sobre la cultura. Pero sus críticos se han percatado de inmediato de que esta formulación no toma suficientemente en cuenta los fenómenos de poder y del conflicto que invariablemente sirven de contexto a la cultura. Los hechos culturales son ciertamente constructos simbólicos — dicen estos críticos-; pero también son manifestaciones de las relaciones de poder y se hallan inmersos en el conflicto social. Más aún, la cultura funciona como máscara de la dominación (Giménez, 1994: 41).

Por tanto, para estudiar las identidades sociales construidas en la actualidad se necesita un concepto de cultura que se comprenda desde la producción simbólica continuamente interrelacionada en aquellas "redes de significación" (Geertz, 1987) que el grupo crea, pero partiendo de la posibilidad del reacomodamiento de las "fronteras de adscripción" a partir del conflicto y la negociación en las relaciones de poder que existen en la colectividad. Al mismo tiempo, de la apropiación permanente de modelos culturales aparentemente ajenos, como alguna vez propuso Fredrik Barth (1976) en aquel célebre debate sobre los procesos étnicos. La cultura no se entiende sino como un espacio de lucha, de transacción permanente entre lo que forma parte de los límites y lo que queda fuera de éstos.

Como este continuo conflicto está supeditado por las relaciones de poder grupales, ello hace que la cultura se torne en una posibilidad comunitaria en construcción en contraste a algo que ya está creado per se. Esto puede observarse en los condicionamientos de carácter normativo, negociados, a los que están permanentemente sujetos los miembros del grupo. Es decir, aquellos límites de adscripción se valoran en el qué se puede y qué se debe apropiar de pautas ajenas a los de la cultura primigenia.

En las regiones étnicas se tienen que tomar en cuenta el performance continuo que los miembros hacen de su cultura; sus préstamos y sus propios aportes y lo que reciclan de manera permanente y sistemática. $\mathrm{Y}$ es precisamente que estos procesos de intercambio continuo pueden observarse en las juventudes indígenas por ser quienes también están sujetas a todos los mensajes y discursos de los contextos globales ${ }^{2}$ (Zebadúa, 2009). 


\section{Las identidades se multiplican}

Los procesos de construcción de las identidades (nacionales, sociales, étnicas, individuales, comunitarias) están siendo hoy día ampliamente discutidos para entender la conformación de las sociedades actuales. Estas identidades se presentan como parte de los conflictos culturales que ocurren dentro de los contextos actuales y que demarcan el análisis de la emergencia de nuevos actores y/o nuevas identidades, acorde con los dramáticos cambios sociales suscitados en el mundo en los últimos años.

En este sentido, la construcción de las identidades tiene ya una nueva dimensión con respecto a la dinámica de contextos anteriores. Este desorden sistémico internacional al que asistimos da pie a la reflexión sobre los caminos que llevan los recursos identitarios de los grupos como parte de su construcción de sentido. Estas nuevas formas de posicionarse identitariamente son paralelas a las dinámicas culturales en las que los espacios locales igualmente tienen trascendencia con respecto a los globales; y cuando se visibilizan las multiplicaciones identitarias pero también las maneras de manifestar el sentido desde lo propio, que en todos los casos sirve para generar discursos alternativos en la apropiación constante de culturas distintas como parte de la "democratización" de la inclusión de las identidades "diferenciales":

En este escenario, la relativa difuminación de las fronteras tradicionales (entre estados, regiones, ideologías, pero también entre saberes y disciplinas), más allá de su efectiva validez política según los casos, ha favorecido el surgimiento $\mathrm{y} / \mathrm{o}$ afianzamiento de las llamadas "minorías" que reivindican una identidad diferencial en un contexto dado. Más que ser entendida en términos numéricos, la idea de minoría o minoritario, en el sentido ya clásico de Deleuze, supone justamente la oposición a aquello instituido como patrón o canon a partir del cual se clasifica o discrimina (la posición masculina, etnocéntrica, heterosexual, por ejemplo). En este sentido, las nuevas identidades diferenciales y minoritarias, cuya visibilidad se acentúa en los distintos contextos culturales, son consideradas por algunos teóricos como positivas, no en sí mismas sino en tanto contribuyen a ampliar el espacio contemporáneo de las democracias (Arfuch, 2000: 62).

Mucho se decía de los escenarios de la globalización como un factor mundial de "homogenización cultural" (Ortiz, 1996). No obstante, ha sucedido lo contrario: presenciamos el auge de movimientos sociales que, desde prácticas y discursos localizados, niegan la mediación uniformadora y tienen como sello la identidad incluso como respuesta de resistencia y contestación hacia el estado de cosas (Yúdice, 2002; Castells, 1998).

Cuando no sucede la homogenización surgen las diversidades sociales, en las que los discursos identitarios no son únicos ni unidimensionales: "De acuerdo con la situación relacional en la que un individuo encuentra lazos de adscripción y pertenencia, la identidad expresa lo que se ha llamado 'geometría variable', con la que cada individuo o grupo puede operar una pluralidad de referencias identitarias" (Guerrero, 2002: 106). Las identidades se observan ahora como "múltiples", según observa Díaz-Polanco (2010), en tanto que son históricas, dinámicas e internamente heterogéneas, como característica de las identidades contemporáneas:

Puede decirse, por tanto, que la identidad múltiple es la regla. Los sujetos no se adscriben a una identidad única sino a una multiplicidad de pertenencias que ellos mismos organizan de alguna manera en el marco de las obvias restricciones sistémicas, pero que están presentes de modo simultáneo [...] En su misma simplicidad, la imagen de diversas camisetas convenientemente colocadas una encima de otra, 
sobre el mismo sujeto, ayuda a ilustrar el fenómeno. Comprender la diversidad, en este caso, requiere considerar tal articulación compleja de planos identitarios, como constitutivos de la noción de los nosotros. La pertenencia identitaria incluye estos diversos niveles o capas, y es preciso que se estudien sus mutuas influencias y contrapesos, y cómo todos ellos contribuyen a sostener y dar sentido a la llamada adscripción cultural (Díaz-Polanco, 2010: 210-211).

\section{La transculturalidad como proceso de confluencia}

Las identidades múltiples forman parte de los procesos sociales de la transculturalidad. Se admite aquí que las identidades múltiples representan una condición, se crean como producto de factores que están presentes en los contextos vigentes en el marco de los préstamos e intercambios culturales. Es una condición porque las identidades que están en este marco de acción forzosamente se multiplican. Mientras que la transculturalidad es un proceso mediante el cual las identidades múltiples se reproducen y se manifiestan como un "tercer espacio". Es la parte donde la multiplicación se convierte en una "nueva identidad" a partir de esos préstamos e intercambios.

Este proceso social (llamado aquí transculturalidad) se promueve en los intersticios del conflicto cultural de las pertenencias, entre lo que es específico y lo que es distinto, para después elaborar nuevos constructos identitarios. La multiplicidad es una característica de las identidades en nuestros días, mientras la transculturalidad es la forma de distinguir y manifestar las nuevas referencias identitarias.

Podemos analizar lasidentidades juveniles indígenas desde un enfoque transcultural, entendido como un proceso social de intersección por el cual convergen distintos patrones culturales sin que estén en una situación de conflicto y que uno sea más prioritario que otro. La transculturalidad es la síntesis mediante la cual confluye el contacto de dos o más elementos culturales y pasa a ser un referente más allá de las unicidades identitarias (Zebadúa, 2010: 92-95)

Con este enfoque podemos observar cuatro elementos para el análisis actual de las construcciones identitarias juveniles: ya no representan la pertenencia grupal única; son "flexibles", los límites acotados en espacios únicos se abren para dar pie a diversas adscripciones; los medios de comunicación, las industrias culturales y el consumo cultural ya son parte imprescindible en la conformación de las identidades juveniles; y finalmente, en estas identidades los jóvenes tienen un intenso intercambio entre su cultura tradicional y los lenguajes globales de los medios de comunicación y el consumo cultural, así las identidades de origen son siempre retroalimentadas.

El primer elemento es el que plantea que las identidades juveniles transculturales ya no representan la pertenencia grupal única. Esto quiere decir que la unicidad con que los grupos identitarios primarios se delimitaban ya no son significativos a la hora de definir el sentido de pertenencia. Así, las identidades juveniles no pregonan el sentimiento integral a una sola pertenencia identitaria, más bien recurren a ésta para tener un punto de partida hacia otros espacios culturales.

El segundo elemento es la flexibilidad con que las identidades juveniles transculturales construyen sus demarcaciones identitarias. Los límites de la identidad se abren y se constriñen de acuerdo con las necesidades estratégicas de los actores juveniles: ya no existen "pertenencias totales" en los momentos de definición identitaria, y se está o no está cada vez que sea pertinente a las propias experiencias y prácticas culturales en turno.

El tercer elemento es la influencia de los medios de comunicación, las industrias culturales y el consumo cultural en la construcción de las identidades juveniles transculturales. En los tiempos actuales, los medios de comunicación y las llamadas industrias culturales forman parte de una compleja estructura 
socio-tecnológica que prácticamente vertebra todo el sistema de información e intercambio de bienes culturales en el mundo. En palabras de Mattelart, "las redes de comunicación en tiempo red están configurando el modo de organización del mundo" (Mattelart, 1998: 113).

En el caso de las juventudes, han sido blanco de consumo (target) (Méndiz, 2005; Zebadúa, 2009) desde la impronta de la globalización y su configuración a partir de los medios de comunicación. Si bien la influencia de los medios es decisiva en la conformación de las identidades transculturales, también se tiene que tomar en cuenta otros posicionamientos juveniles en torno a la construcción de sus identidades (Valenzuela, 2009: 39), aunque siempre tomando en cuenta la perspectiva propia de los actores juveniles al retroalimentar continuamente los mensajes mediáticos mundializados y dejan de ser sujetos pasivos en el momento de ser parte de los medios y el consumo cultural mundializado.

Esto nos permite llegar al último elemento constitutivo de las identidades juveniles transculturales. Los jóvenes son objeto de apropiación mediática, lo que los lleva a convertirse en receptores de los procesos de las industrias culturales, medios de comunicación y el consumo, pero al mismo tiempo reciclan esos discursos de acuerdo con sus propias estrategias culturales y niegan así la supuesta uniformización con su movilidad y transitoriedad identitaria.

\section{Identidades juveniles transculturales}

El constructo propicio para observar la transculturalidad en las juventudes indígenas son las identidades. Si están desarrolladas transculturalmente surgen de la apropiación constante de matrices culturales diferentes a la original. Al nutrirse de múltiples símbolos y significados, se crean espacios de comunicación permanente entre expresiones culturales diferentes entre sí creando, mediante la interpelación y retroalimentación continua, nuevas formas de construcción identitaria que incluso rebasan a las identidades originarias.

La intensa relación que los jóvenes indígenas tienen con el consumo cultural y los medios de comunicación es un hecho que se puede observar en la cantidad de dispositivos culturales con que disponen para dinamizar sus identidades: desde la presencia de emos y chavos banda, de estudiantes y campesinos, de migrantes y roqueros, las juventudes indígenas crean identidades y manifiestan su inclusión en las comunidades donde se desenvuelven, como enuncia Gómez Montt:
Alolargo de estas regiones los medios de comunicación e información tienen una importancia fundamental en la creación y recreación de un espacio propio equivalente al comunitario (Gómez, 2010: 39).

Las identidades transculturales surgen porque ya no representan la unidad identitaria en la adscripción étnica tradicional. Los límites étnicos juveniles se flexibilizan y se demarcan en fronteras cada vez más diluidas para dar pie a escenarios culturales distintos, donde es lo transcultural lo que determina las relaciones de las juventudes contemporáneas (Zebadúa, 2009).

La migración ha sido determinante en este proceso. Las referencias de los migrantes jóvenes en los imaginarios indígenas han logrado que las generaciones presentes perciban de manera distinta su condición social como indígenas. Esto se observa en la flexibilidad de sus discursos; sus dinámicas culturales ya no se esencializan sino "transitan", se mueven constantemente. Esta flexibilidad, más allá de una estrategia cultural, es también una condición dado que los procesos identitarios actuales de corte múltiple por sí mismos tienen el arsenal de respuestas a un crítico estado de cosas que hace buscar nuevas formas de contrarrestarlo y adecuarse deliberadamente a la realidad contemporánea, tan volátil como la simultaneidad de nuestro tiempo: 
Los pueblos indígenas son empujados a una difícil escaramuza por sus identidades, pues se enfrentan asimismo al efecto disolvente que provoca la globalización en sus comunidades tradicionales [...] La crisis general de la comunidad, inducida por la globalización, también está alcanzando a buena parte de los pueblos indios en todas partes. El renovado afán identitario de los indígenas a últimas fechas tiene mucho que ver con el hecho de que esa crisis también los ha tocado, a veces, en partes vitales (Díaz-Polanco, 2010: 207).

En las identidades juveniles indígenas los procesos de permanente reelaboración cultural circulan por ese tamiz formando parte de un escenario cultural en el que estas identidades se formulan en difuminación, con carácter multiplicado, "entrando y saliendo" en los campos de interrelación. En dichos procesos identitarios puede apreciarse, al mismo tiempo, la disputa permanente por lo cotidiano, el sentido de lo propio a contraluz de lo mundializado. Aparece así un espacio discursivo juvenil donde lo que está adentro y afuera de la propia cultura se negocia incesantemente.

Estos espacios se manifiestan en los intersticios culturales que crean los jóvenes indígenas frente a la cultura tradicional como formas de diálogo donde se combinan lo que se tiene de propio y lo que se adopta de lo ajeno. La tensión surgida entre estas dos alternativas se dirime, no sin conflicto, a partir de que cada vez más las nuevas identidades juveniles indígenas son parte del paisaje étnico, aparte que la creación de nuevos sentidos identitarios no crea pérdida de la cultura autóctona. Entonces, las nuevas prácticas de los jóvenes, al establecer intersticios entre lo que es y lo que no es, instauran las condiciones para que sus identidades se flexibilicen y permiten así el constante intercambio cultural: "Es en lo periférico, en los intersticios de los grandes paradigmas, donde se despliegan con fuerza nuevas dinámicas de la cultura" (Herlinghaus, 2003: 1). En los procesos transculturales se está en camino de llegar a una "traducción cultural"
(Castiel, 2001) que dejará de lado la inmutabilidad cultural de las juventudes indígenas para analizarlas desde sus permanentes y ahora visibles construcciones identitarias que también pueden leerse en situaciones de "linde":

(El linde) Parecería ser una palabra que indica terminación, una separación infranqueable entre territorios, una nítida distinción entre espacios. Pero esa impresión puede resultar engañosa, o peor aún, paralizante, en tanto implica la idea de un borde existente, de un punto ciego preconstituido, y no de una producción de la mirada [...] (El linde es) ese "entre dos" que crea un "tercer espacio" de indeterminación, una "tierra de nadie" en el que las identidades (incluidas las de los dos espacios linderos en cuestión) están en suspenso, o en vías de reedefinción [...] (es) el momento del encuentro: es decir, en última instancia, el momento de la lucha; es decir, el momento profundamente político [...] (porque) el concepto de "linde" tiene la ventaja de llamar la atención de un territorio sometido, en su propia delimitación, a la dimensión del conflicto y de las relaciones de fuerza, donde el resultado del combate por la hegemonía [...] es indeterminable pero no indeterminado (Grüner, 2000: 18-19).

Por último, también desde la "desterritorialización" es como podemos analizar la conformación de las identidades juveniles transculturales indígenas. En los actuales contextos globales fenómenos sociales como la migración y la influencia de los medios masivos de comunicación hacen que las identidades juveniles se construyan y manifiesten en redes simbólicas más allá del territorio geográfico. Se prescinde de lo que Valenzuela llama la "simbolización territorial única", porque no se adquieren grados de cohesión determinantes en un sólo campo de identidad específico. Al contrario, éste se disemina y diversifica llegando a "resignificar" y a "reterritorializar" (Pérez, 2008: 33) dichos territorios 
culturales, teniendo como resultado las "identidades transitorias" (Valenzuela, 1997).

A continuación un ejemplo que nos parece demostrativo de la transculturización y desterritorialización de las identidades juveniles indígenas. El nuevo rol que juega en su comunidad de origen un joven indígena totonaco del norte del estado de Veracruz, que migró a Estados Unidos y ahora está de regreso. En opinión de la población de su pueblo el ya es otro puesto que se viste, habla y actúa diferente. Se pinta los ojos y dice que es dark, en su casa tiene discos y videos de grupos europeos, sobre todo nórdicos, que los ha "bajado" de la red. Pero también participa activamente en las festividades de la comunidad, incluso danza en honor del santo patrono; el mismo día en el que baila, se va al baile del pueblo y baila por lo menos siete ritmos diferentes: cumbia, reguetón, salsa, banda, duranguense, cumbia texana y rock. En el baile habla, en totonaco, de su conexión virtual con una red de "darketos" internacionales, vía Internet, y de lo bien que se siente con su familia en su retorno de Estados Unidos. En el baile no viste como dark sino como cualquier joven que va a la moda que aparece en televisión, aunque en sus muñecas tiene dos pulseras negras con dos calaveras blancas y una cadena en el cuello con el símbolo de anarquía; también se coloca vaselina en su cabello, dejándose un copete de puntas enfrente. ¿Qué es lo que hace ser indígena a este joven? O bien, ¿qué es lo que hace no ser indígena? ¿Cuáles son las coordenadas culturales que este joven totonaco emplea para ser lo que quiere ser? Y en todo caso, ¿cuáles podrían ser las epistemes con que la ciencia social puede observar estos procesos? He ahí un imprescindible reto para los análisis de las juventudes indígenas.

\section{Notas}

${ }^{1}$ Esta tendencia la coloca como punto rector y de análisis de lo que sucede en el entorno de nuestro tiempo alcanzando a diversos campos de estudio, otrora de difícil acceso al entendimiento de los procesos simbólicos como una práctica y perspectiva central para el accionar social, por ejemplo, en la economía y muchos estudios empresariales; de igual forma en los estudios agrarios y del campesinado; la psicología social, la filosofía y hasta en el derecho, entre otros espacios de conocimiento, que amplían los límites de sus unidades de análisis para dar cabida a la cultura como referente para la reflexión (Vargas, 2007).

${ }^{2}$ En general es el sector juvenil el que está inmerso en los bienes y mensajes de la globalización, como parte de los discursos de consumo de las grandes industrias culturales.

\section{Bibliografía}

Arfuch, Leonor (2001), "Escenario urbano e identidad cultural”, en Marta M. Palchevich y Luis H. Martínez (coords.), Boletín de la Biblioteca del Congreso de la Nación, núm. 120, Identidad cultural, Argentina: Biblioteca del Congreso de la Nación, pp. 61-74.

Barth, Fredrik (1976), Los grupos étnicos y sus fronteras, México: Fondo de Cultura Económica.

Castells, Manuel (1998), La era de la información. Economía, sociedad y cultura, vol. 2. El poder de la identidad, Madrid: Alianza.

Castiel Menda, Cynthia (2001), "Movimientos migratorios y educación: el desarrollo de la identidad étnico-cultural: un estudio de casos Brasil-Japón", en Encarnación Soriano Ayala, Identidad cultural y ciudadanía intercultural: su contexto educativo, Madrid: La Muralla, pp. 45-72.

Díaz-Polanco, Héctor (2010), "Identidades múltiples en la globalización”, en Daniel Gutiérrez Martínez (coord.), Epistemología de las identidades. Reflexiones en torno a la pluralidad, México: Universidad Nacional Autónoma de México, pp. 199-239.

García Canclini, Néstor (2000), La globalización imaginada, México: Paidós.

Geertz, Clifford (1987), La interpretación de las culturas, Barcelona: Gedisa. 
Ghasarian, Christian (2002), "Por los caminos de la etnografía reflexiva", en Christian Ghasarian et al., De la etnografía a la antropología reflexiva, Argentina: Del Sol.

Giménez, Gilberto (1994), "Comunidades primordiales y modernización en México”, en Gilberto Giménez y Ricardo Pozas, Modernización e identidades sociales, México: Universidad Nacional Autónoma de México, pp. 151-183.

Gómez Montt, Carmen (2010), "Radio, redes y migrantes indígenas: las potencialidades de internet puesta a prueba”, en Mónica Gómez Salazar(coord.), Reflexiones sobre la sociedad del conocimiento y la interculturalidad en México, México: Universidad Nacional Autónoma de México, pp. 39-57.

Grüner, Eduardo (2001), "De culturas e identidades, o que la verdad tiene estructura de ficción", en Marta M. Palchevich y Luis H. Martínez (coords.), Boletín de la Biblioteca del Congreso de la Nación, núm. 120. Identidad cultural, Argentina: Biblioteca del Congreso de la Nación, pp. 13-34.

Guerrero Arias, Patricio (2002), La cultura. Estrategias conceptuales para comprender la identidad, la diversidad, la alteridad y la diferencia, Quito: Abya-Yala.

Herlinghaus, Hermann (2003), "Posmodernidad latinoamericana y postcolonialismo angloamericano. Un debate necesario en torno a una 'nueva' ecología de las identidades", en Diálogos de Comunicación, núm. 31, www.dialogosfelafacs.net/dialogos.../49-04HermannHerlinghaus. pdf, (enero 22 de 2009).

Hernández, Caridad y Margarita del Olmo (2005), Antropología en el aula, España: Síntesis.

Imaz Bayona, Cecilia (2006), "Multiculturalismo y migración internacional. Permanencia y revaloración de la identidad cultural de la migración mexicana en los Estados Unidos", en Daniel Gutiérrez Martínez (coord.), Multiculturalismo: perspectivas y desafios, México: Universidad Nacional Autónoma de MéxicoColegio de México-Siglo XXI.

Mattelart, Armand (1998), La mundialización de la comunicación, Barcelona: Paidós.
Méndiz Noguero, Alfonso (2005), "La juventud en la publicidad", en Concepción Naval y Charo Sádaba (coords.), Jóvenes y medios de comunicación. Revista de Estudios de Juventud, marzo, núm. 68, Madrid, pp. 104-113.

Ortiz, Renato (1996), Otro territorio. Ensayos del mundo contemporáneo, Buenos Aires: Universidad Nacional de Quilmes.

Pérez Ruiz, Maya Lorena (coord.) (2008), Jóvenes indígenas y globalización en América Latina, México: Instituto Nacional de Antropología e Historia.

Terrazas Merino, Maziel (2008), "Jóvenes quechuas del ayllu Chari, La Paz, Bolivia: identidad, globalización imaginarios y bienes culturales", en Maya Lorena Pérez Ruiz (coord.), Jóvenes indígenas y globalización en América Latina, México: Instituto Nacional de Antropología e Historia, pp. 141-160.

Thompson, John B. (1998), Ideología y cultura moderna. Teoría Crítica social en la era de la comunicación de masas, México: Universidad Autónoma Metropolitana.

Valenzuela, José Manuel (1997), "Culturas juveniles. Identidades transitorias. Un mosaico para armar", en Revista Joven-Es, enero-marzo, núm. 3, México, pp. 12-35.

Valenzuela, José Manuel (2009), El futuro ya fue. Socioantropología de l@s jóvenes en la modernidad, México: Colegio de la Frontera Norte, México: Juan Pablos.

Vargas Hernández, José Guadalupe (2007), "La culturocracia organizacional en México", Enciclopedia y Biblioteca Virtual de las Ciencias Sociales, Económicas y Jurídicas, núm. 301, http://www.eumed.net/ libros/2007b/30l/index.html, (3 de abril de 2009).

Yúdice, George (2002), El recurso de la cultura. El uso de la cultural en la era global, Barcelona: Paidós.

Zebadúa Carbonell, Juan Pablo (2009), Culturas juveniles en contextos globales. Cambio y construcción identitaria, México: Universidad Veracruzana-Universidad Veracruzana Intercultural.

Zebadúa Carbonell, Juan Pablo (2010), "La construcción de las identidades juveniles transculturales: 
dispersión de fronteras y pertenencias múltiples", en Juan Pablo Zebadúa Carbonell (coord.), Comunicación ydesarrollocultural, México: Universidad VeracruzanaUniversidad Veracruzana Intercultural. 